\title{
A casualty of the ambulance dispute
}

\author{
GaReTh H. Jones, Senior Lecturer and Honorary Consultant Psychiatrist, \\ Department of Psychological Medicine, University of Wales College of Medicine, \\ Whitchurch Hospital, Cardiff CF4 7XB
}

As well as the more spectacular 999 calls to urgent road traffic accidents and myocardial infarction victims, the ambulance service provides a background care which allows people with chronic and recurring disabilities to remain in their own homes.

\section{Case}

A 70 year old lady was well supported in a psychiatric day hospital, being picked up by ambulance two days a week from her home. She received social support, occupational therapy and haloperidol $10 \mathrm{mg}$ bd. With the ambulance dispute biting, ambulance cover no longer became possible, and taxi transport was arranged in lieu. However, this lady, as a result of many years of recurring paranoid schizophrenia, was extremely suspicious and reclusive, and would not open the door to a strange taxi driver. She gradually withdrew from all social contact, stopped her medication and even her closest relative had to climb through a window to gain admittance. She refused voluntary hospital admission, and although the community psychiatric nurse called daily, would not let her into the house.

She was eventually admitted under Section 3, when it was noticed she had hurt her hand. However, she would not allow it to be examined. After several doses of haloperidol, she was persuaded eventually to display her left hand, which was clawed, useless and mummified, with a loss of sensation as far as the wrist. She admitted that, several days previously, she had plunged her hand into boiling water and had held it there, in response to the commands of her second-person auditory hallucinations, which had recurred during this period.

An urgent opinion from the Burns Service confirmed that the hand was not viable, and amputation was advised. However, she would not consent to this, and as the condition was thought to be neither urgent nor life threatening, she continued under compulsory treatment for schizophrenia on a psychiatric ward. After 14 days of neuroleptic therapy, she gave informed consent for operation, and the hand was amputated. Fortunately, no infection had gained hold, and the wound healed by first intent.

\section{Comment}

This lady illustrates the extreme sensitivity of many mentally ill patients to comparatively minor changes in the social environment (Birley \& Brown, 1970). Recurrences occur from time to time anyway, and may well be associated with a suicide attempt or apparently painless self-mutilation (Feldman, 1988), although neither had been a problem with this individual before. Relapses of schizophrenia can be minimised by maintenance treatment with either oral or intra-muscular dopamine blocking agents (Leff \& Wing, 1971; Curson et al, 1985). Management in this case was made much more difficult by the manifest failure of the Mental Health Amendment Act 1983 in two crucial areas.

The first is that the Act addresses compulsory treatment for mental disorder only, and not the necessity for medical as opposed to psychiatric treatment in patients who are mentally ill or mentally handicapped to such an extent that they cannot give informed consent (Bicknell, 1989). More importantly, it has failed to institute a legal framework for the compulsory preventive treatment of mental illness at home, rather than in hospital, although this has been possible at a technical level for many years. A refusal to accept such treatment is often symptomatic of various psychoses, particularly schizophrenia, and is not usually a logical and informed decision. Until such humane legislation is enacted, it is difficult to see how, despite every reasonable care, tragedies such as this can be prevented.

\section{References}

BiCKNELl, J. (1989) Consent and people with mental handicap. Editorial. British Medical Journal (Clinical Research), 299, 1176-1177.

Birley, J. L. T. \& Brown, G. W. (1970) Crises and life changes preceding the onset or relapse of acute schizophrenia: clinical aspects. British Journal of Psychiatry, 116, 327-333.

Curson, D. A., Barnes, T. R. E., Bamber, R. W., Platt, S. D., HiRSCH, S. R. \& DUFFy, J. C. (1985) Long-term depot maintenance of chronic schizophrenic out-patients: the seven year followup of the MRC fluphenazine/ placebo trial. III. Relapse postponement or relapse prevention? The implications for long-term outcome. British Journal of Psychiatry, 146, 474-480.

Feldman, M. D. (1988) The challenge of self-mutilation: a review. Comprehensive Psychiatry, 29, 252-269.

LEFF, J. P. \& WiNG, J. K. (1971) Trial of maintenance therapy in schizophrenia. British Medical Journal, 3, 599-604. 